http://dx.doi.org/10.12775/szhf.2020.017

\author{
MAREK LECHNIAK \\ John Paul II Catholic University of Lublin \\ E-MAIL: LECHMAR@KUL.PL \\ ORCID: 0000-0002-0768-7963
}

\title{
Jerzy Łośs Epistemic Logic and the Origins of Epistemic Logics
}

The beginnings of non-classical logic date back to the late 1920s, when the first works of J. Łukasiewicz on three-valued logic and A Survey of Symbolic Logic by C. I. Lewis, wherein he presented the first systems of modal logics, appeared. Each of these systems was presented as competitive to classical logic, i.e., characterising the basic operators of sentence logic in a way other than classical logic. Until his death in 1956, Łukasiewicz and his school (e.g., M. Wajsberg axiomatised the $\mathbf{\mathbf { } 3}$ system), in the 1930s and 1940s, developed the idea of many-valuedness, both formally and intuitively (arguments for three-valuedness). On the other hand, the idea of modal logics underwent some fundamental modifications following the work of Gödel, who demonstrated that Lewis's systems can be built as extensions of classical logic. ${ }^{1}$

${ }^{1}$ Gödel provided the axiomatics for systems S4 and S5, while Lemmon provided such axiomatics for systems S1-S4. See Kurt Gödel, "Eine Interpretation des intuitionistischen Aussagen-kalküls", Ergebnisse eines mathematisches Kolloquiums 4 (1933): 34-40; Edward John Lemmon, "New Foundations for Lewis Modal Systems", Journal of Formal Logic 22, 2 (1957): $176-186$. 
In such an approach, the operators of necessity and possibility appear nonextensional.

The program of introducing non-extensional operators to logic was subject to criticism by Łukasiewicz. It is enough to mention here that Łukasiewicz's utterly negative comments were directed, as it seems, towards Von Wright's analysis of modality contained in An Essay in Modal Logic. ${ }^{2}$ Łukasiewicz's remarks come from the second edition of Aristotle's Syllogistic and, therefore, probably from the first half of the 1950s. Łukasiewicz doubts the possibility of the logical characterisation of intensional functions; and this strong extensionalism, dominant in the Polish logic of that period, was probably a challenge that was taken up by Jerzy Łoś. This is evidenced both by the title of the article Logiki wielowartościowe a formalizacja funkcji intensjonalnych (Manyvalued logics and formalisation of intensional functions), ${ }^{3}$ a direct response to the problem posed by Łukasiewicz, as well as his first paragraph. ${ }^{4}$ The use of the matrix method ${ }^{5}$ to characterise the intensional functions led Łoś to construct the world's first system of epistemic logic. ${ }^{6}$ One should highlight

2 Georg Henrik Von Wright, An Essay in Modal Logic (Amsterdam, 1951); “[...] if $p$ is equivalent to $q$, then always if $\delta$ of $p, \delta$ of $q$, i.e. if $p$ is true, $q$ is true, and if $p$ is false, $q$ is false; similarly if $p$ is necessary, $q$ is necessary, and if $p$ is possible, $q$ is possible. This seems to be perfectly evident, unless modal functions are regarded as intensional functions, i.e. as functions whose truth-values do not depend solely on the truth-values of their arguments. But what in this case the necessary and the possible would mean, is for me a mystery as yet" (Jan Łukasiewicz, Aristotle's Syllogistic from the Standpoint of Modern Formal Logic (Oxford: Clarendon Press, 1957), 140).

3 Kwartalnik Filozoficzny 17, 1-2 (1948): 59-78.

4 "In this work, I would like to present a certain concept of formalising intensional functions and show their relation with the functions of many-valued logics. Furthermore, I would like to point out the possibility, or even a necessity, of referring to many-valued logics when formalising such functions. Yet, it is not a matter of referring to the concept of a sentence with a value other than truth or false, but of a formal procedure which is specific to manyvalued logics which serves the methodological research of these systems" (Jerzy Łoś, "Logiki wielowartosciowe a formalizacja funkcji intensjonalnych", Kwartalnik Filozoficzny 17, 1-2 (1948): 59).

5 One year after the discussed article was released, Łoś published his doctoral dissertation "O matrycach logicznych", Prace Wrocławskiego Towarzystwa Naukowego, Seria B, 19 (1949).

${ }^{6}$ Lośs work is from 1948 and its presentation by Suszko appeared, which is worth emphasising, in Journal of Symbolic Logic in 1949 and the book An Essay in Modal Logic by Von Wright, wherein he presents an epistemic interpretation of systems T, S4 and S5, was published in 1951. 
the original characteristics of the epistemic operator provided by Łoś, as it is not a simple interpretation of the operator of necessity in standard modal logics. The description of the epistemic operator presented by Łoś is, to a certain extent, similar to the description of the operator of truth in a moment in time, ${ }^{7}$ and the use of sentence logic with quantifiers significantly increases the means of expression of that sentence logic. ${ }^{8}$

In this article, ${ }^{9}$ I analyse the main theses of system $\mathbf{L}$ of Jerzy Łośs epistemic logic, especially in the aspect of non-formal semantics. ${ }^{10}$ In other words, the main theses of Łośs system will be juxtaposed with the basic theorems of the theory of rational behaviour. Next, I will present Rescher's attempts to place Łośsystem in a certain hierarchy of systems of logics and Marciszewski’s attempts to modify Łośs system in order to remove those theses, which are inconsistent with the main theorems of the theory of rational behaviour.

7 This is about another article published at the same time by Łoś, Podstawy analizy metodologicznej kanonów Milla, wherein he characterises the notion of truth in a given moment of time; several axioms of that system are analogous to those for the notion of assertion.

8 Łośs systems have been extensively studied over the last two decades in such works as: Tomasz Jarmużek, "Minimal Logical Systems with R-operator: Their Metalogical Properties and Ways of Extensions", in: Perspectives on Universal Logic, eds. J. Bezieau, A. Costa-Leite (Italy: Polimetrica Publisher, 2007), 319-333; Tomasz Jarmużek, Marcin Tkaczyk, Normalne logiki pozycyjne (Normal positional logics) (Lublin: Wydawnictwo KUL, 2015); Tomasz Jarmużek, Marcin Tkaczyk, "Expressive Power of the Positional Operator R: A Case Study in Modal Logic and Modal Philosophy", Ruch Filozoficzny LXXV, 2; Marcin Tkaczyk, Logika czasu empirycznego (Lublin: Wydawnictwo KUL, 2009); Marcin Tkaczyk, "Negation in weak positional calculi", Logic and Logical Philosophy 22 (2013); Anna Karczewska, "Maximality of the Minimal R-logic", Logic and Logical Philosophy 27 (2018); and Tomasz Jarmużek, Aleksander Parol, "On Some Language Extension of Logic MR: A Semantic and Tableau Approach", Roczniki Filozoficzne 68 (2020) 4: 345-366, which generalised their results and demonstrated their originality and relevance for further research, particularly in terms of temporal logics.

9 I discussed these issues in "Logika epistemiczna Jerzego Łosia a teoria racjonalnego zachowania" ("Epistemic logic of Jerzy Łoś and rational choice theory"), Roczniki Filozoficzne 36, 1 (1988) and Przekonania i zmiana przekonań (Beliefs and belief change theory) (Lublin: Wydawnictwo KUL, 2011).

${ }_{10}$ Non-formal semantics is the last of the four determinants of the system of logic presented by S. Haack; according to Haack, the existence of the formal model itself, in which the theses of the system are fulfilled, is not sufficient for a formal system to be considered a system of logic (Susan Haack, Philosophy of Logics (Cambridge: Cambridge University Press, 1978)). 


\section{1. Łośs Logic of Assertion}

As indicated earlier, the article by Łoś aimed at demonstrating that it is possible (i.e., it is not contradictory) to formally analyse expressions that feature significant non-extensional functions. In other words, it is possible to define a system that formally characterises an intensional function, one to which the law of extensionality does not apply (assuming a value different from the distinguished value) for contexts containing a non-classical operator.

The starting point in Łośs deliberations is the analysis of the intensional function "The person $x$ accepts that $p$ ". Its logical value is not determined solely by the logical value of sentence $p$ because, for instance, the sentence "John accepts that $2+2=4$ " and the sentence "John accepts that 3 is the root of the equation $x^{2}-3 x+2=0$ " are both true despite the fact that the sentence argument of the former is true and that of the latter is false. The expression $L_{x} p$ is, therefore, introduced; however, it should be understood "not as a description of some mental act but in the sense that, for instance, I assert that the Earth is round, as of the moment I found out about it, although this sentence has not been the subject of my thoughts all this time. If I were asked about the shape of the Earth during this period, I would say it is round". ${ }^{11}$ So, the author of system $\mathbf{L}$ understands the function of assertion as a disposition to certain behaviour. At the same time, he stipulates that, for technical reasons, he presents the simplest system possible, which does not reflect all the intuitions people associate with this term. ${ }^{12}$

\subsection{The Language of System $\mathbf{L}$}

The symbols of system $\mathbf{L}$ are as follows:

1. Proposition variables: $p, q, r, \ldots$;

2. Name variables: $x, y, z, \ldots$;

3. Operators of the classical propositional calculus (CPC);

11 Łoś, Logiki wielowartosciowe a formalizacja funkcji intensjonalnych, 70.

12 The analyses of the various concepts of belief and divisions of beliefs made on the basis of different criteria can be found in Lechniak, Przekonania i zmiana przekonań. 
4. Quantifiers that bind name variables and quantifiers that bind sentence variables;

5. The $L$ constant, a sentence-forming operator of two arguments for name and sentence arguments, whereas the expression $L_{x} p$ may be read as " $x$ asserts that $p$ ";

6. Auxiliary expressions.

The meaningful expressions of system $\mathbf{L}$ are as follows:

1. Meaningful expressions of the classical propositional calculus;

2. Expressions of the form $L_{\alpha} \beta$, where $\alpha$ is a unitary-name variable and $\beta$ is an expression with a syntactic sentence category;

3. Expressions created from expressions 1., 2. using the operators of the classic propositional calculus and quantifiers.

\subsection{Axioms, Rules and Main System Theses}

The rules of inference include the rule of substitution, detachment, extensionality (for extensional contexts) and rules for quantifiers. Axioms ( $L_{x} p$ we read: $x$ asserts that $p$ ) are as follows:

$$
\begin{aligned}
& L_{x} p \equiv \neg L_{x} \neg p ; \\
& L_{x}((p \rightarrow q) \rightarrow((q \rightarrow r) \rightarrow(p \rightarrow r))) ; \\
& L_{x}((\neg p \rightarrow p) \rightarrow p) ; \\
& L_{x}(p \rightarrow(\neg p \rightarrow q)) ; \\
& L_{x}(p \rightarrow q) \rightarrow\left(L_{x} p \rightarrow L_{x} q\right) ; \\
& (\forall x) L_{x} p \rightarrow p ; \\
& L_{x} L_{x} p \equiv L_{x} p .
\end{aligned}
$$

(L1) states that anyone who faces a pair of contradictory sentences must assert one of them and reject the other (i.e., " $x$ asserts that $p$ " is the same as "it is false that $x$ asserts that no- $p$ "). (L2.1-L2.3), together with (L3), state that all people use the logic of the classical propositional calculus (i.e., assert Łukasiewicz's axioms and use the rule of detachment). (L4) refers to 
collective knowledge, stating that the sentence asserted by all is true. ${ }^{13}$ (L5), on the other hand, is a reduction thesis that allows all iterations of operator $L$ to be substituted by a sentence that contains only a single operator.

Some system definitions and theorems (defined expressions $S p$ and $p=q$ are read as "it is disputable that $p$ " and " $p$ is equal (epistemically) $q$ ", respectively) are listed below:

$$
\begin{aligned}
& S p={ }_{d f} \exists x \exists y\left(L_{x} p \wedge L_{y} \neg p\right) ; \\
& (p=q)=_{d f} \forall x\left(L_{x} p \equiv L_{x} q\right) ; \\
& S p \rightarrow S(\neg p) ; \\
& \neg S(p \rightarrow p) ; \\
& \neg\left(L_{x} p \wedge \neg L_{x} p\right) ; \\
& L_{x} p \vee L_{x} \neg p ; \\
& L_{x}(p \wedge q) \equiv L_{x} p \wedge L_{x} q ; \\
& p \rightarrow \exists x L_{x} p ; \\
& \neg L_{x} p \rightarrow L_{x} \neg L_{x} p ; \\
& \exists p S p .
\end{aligned}
$$

The non-extensionality of operator $L$ is demonstrated by the argument that the thesis of the system is not an expression stating that if $p \equiv q$ and $x$ asserts that $p$, then $x$ may not assert that $q$, i.e., the thesis of the system is not (F1):

$$
(p \rightarrow q) \rightarrow\left((q \rightarrow p) \rightarrow\left(L_{x} p \rightarrow L_{x} q\right)\right)
$$

The collective context of this non-extensionality is worth emphasising here. Łoś interpreted operator $L$ by means of a many-valued matrix constructed in the following way:

13 Rescher's term "collective knowledge" (1968) is a bit of an overstatement - here we mean that everyone asserts that $p$, and in that sense one could say that such a collection of people, understood collectively, know that $p$. In a proper sense, the collectivity of a set of people is usually connected with their arrangement, structure and organisation and we do not have that here. It is worth adding here that axioms (L1-L4) have their counterparts in the mentioned logic of empirical time, wherein the equivalent (L4) is read as "If at any time $p$, then $p$ " and can be treated as a temporal equivalent of axiom (T) (Loś reads it as "If $p$ occurs at any time, then $p$ can be asserted as the system's thesis"; then $p$ could be considered as knowledge in the context of previous discussions (a non-refutable belief)). 


\begin{tabular}{c|c|c}
$L$ & $A$ & $B$ \\
\hline 0 & 0 & 0 \\
$\frac{1}{3}$ & 1 & 0 \\
$\frac{2}{3}$ & 0 & 1 \\
1 & 1 & 1
\end{tabular}

The letters $A$ and $B$ represent two cognising entities (it is enough to accept two entities to demonstrate the non-extensionality of operator $L$; the number of cognising entities in this system is arbitrary - in this sense the system does not require existential assumptions). These entities may or may not agree on an issue, and the sentence they are asserting may be true or false (since the issue of true or false sentences is not taken into account). All sentences can be divided into four subsets with regard to assertion by $A$ and $B$ : the first is comprised of sentences not asserted by any entity and the second of sentences asserted by $A$ but not by $B$ and so on. The matrix values must, therefore, be interpreted in an epistemic way: 1 - " $p$ is asserted by both entities", $\frac{2}{3}$ - " $p$ is asserted by $B$, but not by $A$ " and so on. Implications and negative matrices are created from the multiplication of ordinary bivalent matrices, i.e., they have a form:

\begin{tabular}{c|cccc|c}
$\rightarrow$ & 0 & $\frac{1}{3}$ & $\frac{2}{3}$ & 1 & $\neg$ \\
\hline 0 & 1 & 1 & 1 & 1 & 1 \\
$\frac{1}{3}$ & $\frac{2}{3}$ & 1 & $\frac{2}{3}$ & 1 & $\frac{2}{3}$ \\
$\frac{2}{3}$ & $\frac{1}{3}$ & $\frac{1}{3}$ & 1 & 1 & $\frac{1}{3}$ \\
1 & 0 & $\frac{1}{3}$ & $\frac{2}{3}$ & 1 & 0
\end{tabular}

The four-value matrix has a formal character; semantically, it would be difficult to interpret it intuitively. If the values of the table refer to the assertion 
(rejection) of sentences by individual subjects, how would one understand the fact that $\neg \frac{1}{3}=\frac{2}{3}$ ? After all, $\frac{1}{3}=$ " $A$ asserts $p$ and $B$ does not assert $p$ ". It is not that " $A$ asserts $p$ and $B$ does not assert $p$ " should then be distributed, according to de Morgan's law, to three possibilities and not just one; that is to say " $A$ does not assert $p$ and $B$ asserts $p$ ". The above matrices make it possible to show that (F1) is not the thesis of system $\mathbf{L}$. All system theses fulfil these matrices, while the expression (F1) does not (for $p=\frac{1}{3}, q=0$, $x=A$ it assumes the value of $\frac{1}{3}$ ). Therefore, the operator $L$ is non-extensional. This non-extensionality is guaranteed by the assumption of a multiplicity of entities; one of them may assert a given sentence and the other may not assert a sentence that is equivalent thereto. Assuming that the beliefs of individual entities are complete, it is suggested that strongly disputable beliefs exist as a consequence. Łoś provided the following definition of disputable beliefs:

$$
S p={ }_{d f} \exists x \exists y\left(L_{x} p \wedge L_{y} \neg p\right) .
$$

The system is many-valued in the sense that single-argument operators, other than bivalent operators such as "It is disputable that", can be defined on its basis. This disputability can be interpreted as hesitation if we were to consider the system as referring not to many entities but to the beliefs of one entity at different points in time (we remember that Łoś built a parallel system for the notion of "true at moment $t$ "). We would then have an equivalent definition of disputability:

$x$ hesitates (has a varying belief) with respect to $p={ }_{d f}\left(\exists t_{1}, t_{2}\right)\left(L_{x, t_{1}} p \wedge L_{x, t_{2}} \neg p\right)$.

Then, it would be possible to understand Łośs remark that the system is non-existential, i.e., we do not have to assume a defined number of entities. Łoś emphasised that "we can enrich system $\mathbf{L}$ in such a way that it can only be interpreted by using matrices with a class of substitutes for name variables (so, in a way, the class of people it refers to) greater or equal to any natural number $n$. For instance, for $n=1$, it is enough to assume an axiom (L6) with the form of $\exists p S p .{ }^{\prime 14}$ For one subject it is not possible to accept disput-

${ }^{14}$ Łoś, Logiki wielowartościowe a formalizacja funkcji intensjonalnych, 77. 
able sentences in the sense that the entity does and does not assert the same sentence (axiom (L1) proposes a non-contradiction). Incidentally, Łośs system would lose its multivalence if it were not treated as a system of collective beliefs but, as Hintikka suggested, as one describing a specific state of a single cognising entity (we would then rule out the change of beliefs in time). Then axiom (L4) would turn into a simple axiom (T) (the quantification $\forall x$ for one entity may not be taken into account) and the system would turn out to be (at least) as strong as KT45; leaving out axiom (L4) we would obtain a system at least as strong as KD45 - the non-contradiction of operator $L$ is guaranteed by axiom (L1).

\section{Rational Behaviour}

The notion of rational behaviour is assumed in many disciplines of humanities. ${ }^{15}$ This is the case in economics (rational purchaser, rational market, rational manufacturer), sociology, history (rational reliable informant), psychology, and so on. The concept of rational behaviour has been studied in the methodologies of these sciences. There are also theories of rational behaviour that reconstruct the relevant theoretical assumptions about the structure of behaviour. ${ }^{16}$ "However, the problem of adequacy of the proposed [for exam-

15 For the theory of rational behaviour see Jerzy Giedymin, Problemy, założenia, rozstrzygnięcia (Problems, assumptions, solutions) (Poznań, 1964), 92-103; Jerzy Kmita, Leszek Nowak, Studia nad teoretycznymi podstawami humanistyki (Sudies on theorethical foundations of science) (Poznań, 1968), 101-117; Leszek Nowak, Zasady marksistowskiej filozofii nauki (Warszawa, 1974), 201-203; and Wojciech Patryas, Idealizacyjny charakter interpretacji humanistycznej (Poznań, 1979) (two chapters in this work are devoted to the presentation of a certain approach to this theory together with the gradual concretisation of its individual theorems).

${ }^{16}$ Although everyone assumes that behaviour (broadly defined as thinking and acting) should be rational, disputes arise when it comes to determining what this rationality should consist of. This work adopts the so-called idealising concept of rational behaviour developed in the Poznan School as part of the idealising concept of science. The very operation of idealisation, sometimes called the Galileo abstraction, which is an operation of capturing a certain feature in its borderline occurrence, is used widely in empirical sciences to create (counterfactual) models of reality. Unfortunately, other approaches, dubbed as more realistic 
ple, by the theory of rational behaviour - M. L.'s remark] logical reconstruction is not positively soluble in empirical terms, i.e., a positive solution to this problem does not result from empirical data (since the reasons tacitly accepted by researchers are generally not realised), it is in principle negatively soluble since its solutions can generally be falsified; the course of research practice excludes in certain cases the possibility that a given logical reconstruction of this research premise is adequate". ${ }^{17}$ Thus, we can assume the findings of the theory of rational behaviour as a (fairly) adequate reconstruction of the concept of rational behaviour found in the humanities and, in this light, analyse system $\mathbf{L}$ to determine the extent to which the model of beliefs assumed by this system coincides with that of rational beliefs implied by the theory of rational behaviour.

Generally speaking, human behaviour is rational when it is determined by knowledge and accepted norms and free from emotional and volitional factors. Thus, the ordered triple is rational behaviour $\left\langle W_{i}, N_{k}, c_{l}\right\rangle$ where $W_{i}$ means the knowledge (beliefs) of a certain individual at a certain place and time, $N_{k}$ is a set of norms accepted by that individual and $c_{l}$ is an action determined by $W_{i}$ and $N_{k}$. Knowledge $W_{i}$ determines a set of actions to be possibly taken in a given decision-making situation (determines the class of actions $c_{l}$ ) and the possible consequences of these actions. ${ }^{18}$ This knowledge is defined from the "formal side" (that it is undeniable, that it is a system, and so on) and the "subjective" side (that the actions and their effects complement each other and exclude, based on the knowledge of $W_{i}$, that the knowledge of $W_{i}$ refers to the way the action $c_{l}$ is executed and that on the basis of the knowledge of $W_{i}$ and preferences set out by the system of standards $N_{k}$ the action $c_{l}$ leads to the effect $n_{i_{k}}$ and so on). ${ }^{19}$ In the context of epistemic logic,

by their authors, e.g., the concept of minimal rationality (Christopher Cherniak, "Minimal Rationality", Mind 90 (1981)), are not more useful than the concept of idealisation. This minimal rationality is characterised by weakening ideal conditions using simple means, e.g., by replacing "all" (knows all the theses of logic) by "some" - in Cherniak, "rationality of the finite entity is an idealised rationality corrected for finite cost and ability" (C. E. Hooker, "Idealisation, Naturalism, and Rationality: Some Lessons from Minimal Rationality", Synthese 99 (1994): 216).

${ }_{17}$ Kmita, Nowak, Studia nad teoretycznymi podstawami humanistyki, 12.

18 Ibidem, 110-112.

19 Nowak, Zasady marksistowskiej filozofii nauki, 102. 
we are particularly interested in the formal characteristics of the knowledge (beliefs) of the entity. These characteristic features consist of several determinants that assume different variations depending on the degree of idealisation in a given variant of the rational behaviour theory. And so, it is claimed that the following conditions are met: ${ }^{20}$

(a) $x$ in the moment $t$ asserts the knowledge of $W$;

(b) the knowledge of $W$ is non-contradictory;

(c) $x$ asserts the logical consequences of the sentences it asserts;

(d) knowledge of $x$-a is true;

(e) $x$ is endowed with a certain self-awareness.

Condition (a) is a realistic condition that advocates the existence of an entity with rational beliefs. Condition (b) is quite universally accepted. In a maximally idealised version, (b) states that $x$ never commits a contradiction, i.e., for every sentence asserted by $x$ it is not that $x$ asserts two contradictory sentences. The weaker (less idealised) versions of this theorem limit the non-contradiction proposed by (b) to a certain period of time, for instance to a set of sentences remembered at that time. ${ }^{21}$ The strength of this theorem depends on the position taken on the subject's deductive capacity. Nowak ${ }^{22}$ and Patryas ${ }^{23}$ included the postulate (b) among quasi-idealising theorems, i.e., those that are true in simple decision-making situations. Some simplifying assumptions are required here such as the lack of ambivalent attitudes (problems with making decisions), memory disorders and affections. Issue (c), the so-called problem of logical omniscience, is widely discussed in the literature. ${ }^{24}$ In the strongest version, it is stated that if $x$ asserts that $p$, it asserts all the logical consequences of that sentence. Therefore, we proposed the following two properties $x$ :

20 Wojciech Patryas, Uznawanie zdań (Warszawa: PWN, 1987), 107-112.

21 Poczobut conducted an in-depth analysis of various concepts of (non-)contradictions (2000); cf. also Lechniak, Przekonania i zmiana przekonań, 123-128.

${ }^{22}$ Nowak, Zasady marksistowskiej filozofii nauki, 203.

23 Patryas, Uznawanie zdań, 107-112.

${ }^{24}$ For instance, ibidem, 93-107; Cherniak, Minimal Rationality, 35-61; and Lechniak, Przekonania i zmiana przekonań, 128-135. 
1) $x$ asserting the sentence $p$ and asserting that $p$ implies $q$ also asserts the sentence $q$;

2) $x$ potentially has "logical omniscience" at its disposal, i.e., it can decide whether each sentence is a logical thesis.

In such a strong version, condition (c) must be considered an idealising theorem, i.e., no (human) cognising entity has the feature advocated by this assertion to the extent required by this condition. A less idealised version of condition (c) is limited to the theorem that $x$ asserts only those consequences of sentence $p$ that it perceives at the time. ${ }^{25}$ This issue is related to the problem of how many schemes of inference a particular individual knows. Sometimes condition (c) is questioned. Chisholm ${ }^{26}$ pointed to the example taken from Pseudo-Scotus, according to which the entity $x$ can assert two sentences, but each individually, and cannot be skilful enough to juxtapose them (and thus to see the logical connection between them). However, the deductive efficiency of the entity in a weaker or stronger version is almost universally asserted as one of the basic (or even decisive) conditions for the rationality of the cognising entity's beliefs, although there was a discussion about which theses (rules) of logic the subject should know to deserve to be called (minimally) rational.

The problem of the truth of $x$ 's beliefs is also under discussion. Some authors do not consider the truth of the sentences asserted by the entity a feature significant for its rationality. Nowak, by attributing a "quasi-idealising" theorem status to postulate (d), considers the truth of beliefs to be a feature available to the human entity. If the sentences asserted by $x$ are, by virtue of the very fact of being asserted, guaranteed to be true, then the assertion can be attributed to the assertion of $x$. Of course, if one asserts the individual infallibility of the cognising entity (postulated by axiom $(\mathrm{T})$ ), the difference between knowledge and beliefs is lost. If we want to maintain this difference, we can postulate that beliefs are sentences that have been subjectively

25 Extensive analyses on how to restrict the postulate of logical or deductive omniscience may be found in Ronald Fagin, Joseph Halpern, Yoram Moses, Moshe Vardi, Reasoning about Knowledge (The MIT Press, Cambridge MA, 1995), 309-362; cf. also Lechniak, Przekonania i zmiana przekonań, 225-236.

${ }^{26}$ Roderick Chisholm, “The Logic of Knowing”, Journal of Philosophy 60 (1963). 
considered true, even though they can be false due to the fallibility of human entities. ${ }^{27}$ Condition (e) is slightly different from the previous conditions. For now, let us simply mention that determining the extent to which entity $x$, which aspires to be rational, should have an understanding of the sentences that it asserts depends on certain philosophical decisions that refer to the value of introspective sentences, the assumed concept of consciousness, and so on. ${ }^{28}$

\section{Analysis of Łośs System in Light of the Postulates of Rational Behaviour}

The axioms (and theses) of system $\mathbf{L}$ can be treated as implying theorems that idealise, in a varying degree, the notions of the cognising entity, characterised by the system, that were asserted as important. Here, we can compare these theorems with the relevant constatations adopted in the theory of rational behaviour.

Let us start our analysis with the non-formal implications of axiom (L4), which states that if sentence $p$ is asserted by all people it is true. So, axiom (L4) expresses a theorem of collective infallibility. This, of course, does not mean that every entity is infallible; therefore, axiom (L4) does not provide an effective criterion for the truth of the sentence asserted by $x$. Thus, it is possible to allow the possibility that a sentence asserted by a particular $x$ is false, i.e., it is fallible. If, on the other hand, we were to call such type of assertion in which the truth of the asserted sentences is guaranteed an assertion, operator $L$ would not describe the concept of assertion. So, if a belief is asserted by every subject of a given population, it becomes common knowledge. This

27 Byrd showed that if the concepts of knowledge and true belief are analysed in isolation from each other, there is no difference in their (formal) behaviour; a difference only emerges if the two concepts are analysed at the same time. See Michael Byrd, "Knowledge and True Belief in Hintikka’s Epistemic Logic”, Journal of Philosophical Logic 2 (1973).

${ }^{28}$ Hintikka was of a different opinion in this matter as he tried to evoke only logical reasons in the discussion on the application of the rules corresponding to axioms (4) and (5) in epistemic contexts. 
population may comprise of a community of scientists or even a system of knowledge. A simple consequence of axioms (L4) and (L1) is the thesis (L11), which states that for any true sentence there is $x$ that asserts this sentence (and its negative version (L11a) $\neg p \rightarrow \exists x L_{x} \neg p$, which Rescher calls Lincoln's thesis (as the president used to say that it is impossible to fool everyone). ${ }^{29}$ This is an optimistic theorem as it expresses a belief about the value of collective knowledge acquisition. However, with some simplifying assumptions (e.g., the assumption that the main interests of each member of the population include cognitive interests or that there is an efficient circulation of information), one can consider (L4) and its consequences as aptly describing the community of cognising entities. As we can see, (L4) implies less things than condition (d), which was adopted in the theory of rational behaviour. Thus, the upper limits of human idealised cognitive abilities are not exceeded here. Simultaneously, a consequence of (L4) is that all people agree on some truths. This is the case, for instance, when the theses of classical logic or some other common truths are concerned; this is stated in thesis (L7).

In the context of (L4), let us analyse axiom (L1), which can be read as follows: "man $x$ asserts that $p$ " is the same as "it is not true that $x$ asserts that not- $p$ ", i.e., "from two contradictory sentences every man has to assert one and reject the other". This axiom has two implications:

$$
L_{x} p \rightarrow \neg L_{x} \neg p
$$

(equivalent on the basis of classical propositional calculus with $\left.\neg\left(L_{x} p \wedge L_{x} \neg p\right)\right)$, and

$$
\neg L_{x} \neg p \rightarrow L_{x} p,
$$

which, with respect to the classical propositional calculus, is equivalent to $L_{x} p \vee L_{x} \neg p$.

29 Marciszewski refers to it as the thesis of epistemic democracy. 
These implications express the epistemic principle of non-contradiction and the epistemic principle of the excluded middle, i.e., the theorem of completeness of belief set $x$, respectively.

(L1a) states that belief set $x$ is non-contradictory; it is not that at the same time $x$ asserts that $p$ and $x$ asserts a sentence that contradicts $p$ (not- $p$ ). In this form, (L1a) expresses the quite commonly accepted (as one of the basic ones) condition of non-contradiction of beliefs of a rational entity (in our juxtaposition, condition (b)). Debatable, however, is implication (L1b), in opposition to (L1a), which states that for each sentence $p, x$ asserts that sentence or asserts a sentence that contradicts it (i.e., $x$ must assert one sentence from two contradicting ones). Considering (L1b) without reference to other theses of the system, we come to the conclusion that system $\mathbf{L}$ may assume the omniscience of the cognising entity. (L1b) is a simple consequence of the theorem of the entity's omniscience, which, in the language of system L, would have the following form:

$$
p \rightarrow L_{x} p^{30}
$$

This theorem can be read as follows: for any sentence $p, x$ asserts that sentence (or with a certain interpretation: $x$ knows every sentence and hence the omniscience). Theologians sometimes assign this attribute to the Absolute. St. Thomas Aquinas wrote, "It is God's property [...] that he knows everything without much inquiry" 31 or (elsewhere): "God by his nature knows not only himself but also all things." ${ }^{32}$ However, regarding omniscience as an attribute of even the most idealised human cognising subject is difficult. ${ }^{33}$ However, system $\mathbf{L}$ directly postulates much less because of only the completeness of the set of beliefs. The problem that arises here is whether the fact that a given thesis is a simple consequence of the rejected thesis disqualifies the former.

30 Since we have $p \rightarrow L_{x} p$ and $\neg p \rightarrow L_{x} \neg p$. The latter is equivalent to $\neg L_{x} \neg p \rightarrow p$; thus, from the law of conditional syllogism, we have $\neg L_{x} \neg p \rightarrow L_{x} p$, i.e., (L1b).

31 STh I 79, 10 ad 2.

32 STh I 87, 1.

${ }^{33}$ Every human cognising subject does not know about the existence of many judgments and, thus, does not assert many $p$ by virtue of the lack of cognitive access; it is hard to assume, however, that they assert their negation on that account. 
One can point to an interpretation where (L1b) would rather express the weaknesses of the human cognising subject. System $\mathbf{L}$ does not guarantee, as already indicated, an effective criterion for deciding which sentences should be asserted by the entity. Since (L1b) "forces" an epistemic determination, making the entity assert one and reject the other for each pair of contradictory sentences, the entity sometimes has to act as if "in the dark" in the absence of individual infallibility (axiom (L4), which is too weak). Without sufficient grounds for asserting a sentence, the entity cannot simply abstain from judgment but asserts it. In other words, proposition (L1b) prescribes a certain unreasonable behaviour, forcing the assertion of false sentences. This postulate is, therefore, undesirable in a system that is supposed to characterise rational assertion.

Marciszewski proposed the limitation of the completeness of the entity's beliefs in two stages. In the first, (L1b) is removed from the axioms of system $\mathbf{L}$, leaving the issue of completeness unresolved. In the next, negation (L1b) is axiomatically accepted. Thus, the possibilities of the cognising subject are limited from above because its consequence is the negation of expression $(\alpha)$, which states that there is no omniscient being.

In the theory of rational behaviour, the deductive connection of beliefs (also called the epistemic principle of consequence) is accepted as one of the basic conditions of rationality. This was referred to in condition (c) of rationality. In its most idealised form, this condition states that the set of beliefs $x$ is a "system", i.e., if $x$ asserts $p$ and $q$ is the logical consequence of $p$ then $x$ asserts $q$ too. In system $\mathbf{L}$ this condition is met but in a less idealised form. Axiom (L3) states that while $x$ asserts that $p$ implies $q$ and that $p$ also asserts that $q$. So, this is the epistemic equivalent of modus ponens. In this form it is difficult to question (L3). However, system $\mathbf{L}$ assumes axioms (L2.1-L2.3), which state that $x$ asserts Łukasiewicz's axioms of the classical propositional calculus. Thus, the axioms propose the "logical omniscience" of the rational entity. This is a consequence of the fact that by asserting the axioms of classical propositional calculus and having an epistemic equivalent of the detachment rule, $x$ is in a disposition to decide about each expression, whether it is the thesis of the classical propositional calculus or not. Instead of (L2), the following rule is often provided: 


\section{$\frac{\vdash_{\mathrm{CPL}} \phi}{\vdash L_{x} \phi}$}

which states that if expression $\phi$ is the thesis of the classical propositional calculus (or, more broadly, the thesis of classical logic), the expression " $x$ asserts that $p$ " is the thesis of the system of epistemic logic. Thus, according to the rule, the epistemic logic system is built on the classic propositional calculus. Therefore, if the appropriate conditions are met (e.g., the rational entity has enough time and has undergone the appropriate logical training), the subject will assert every thesis of logic. It is easy to concertise this theorem. It is enough, for instance, to limit the set of theses asserted by $x$ to the most obvious ones (let us say to those that are equivalents of the rules of the natural deduction system of the propositional calculus). ${ }^{34}$ (L2) and (L3) lead to a meta-systemic rule that, on the basis of asserting a given expression, allows all its logical consequences to be asserted and takes the following form:

$$
\frac{L_{x} \phi, \vdash \phi \rightarrow \psi}{L_{x} \psi}
$$

This rule states the same as condition (c) of rationality in its strongest form. ${ }^{35}$ This, of course, is the result of postulating logical omniscience.

System $\mathbf{L}$ has another axiom that defines the self-diagnostic possibilities of the entity, i.e., an axiom that refers to the scope of self-knowledge of the cognising entity - axiom (L5). From the formal point of view, axiom (L5) is the so-called axiom of reducibility as it allows the formulas of $L_{x} L_{x} \phi$ with

${ }^{34}$ More precisely, one would have to provide the Gödel rule in the version with the operator of possibility:

$$
\frac{\vdash_{\mathrm{CPL}} \phi}{\vdash \diamond L_{x} \phi}
$$

The usual not-weakened Gödel's rule is dispositional in nature (this disposition can be formally interpreted by the operator of possibility) but "forces" the entity to acknowledge every thesis of the classical propositional calculus.

${ }^{35}$ Nicholas Rescher, Topics in Philosophical Logic (Dordrecht: Reidel Publ., 1968), 251. 
multiplied operator $L$ to be reduced to the form with a single operator $L$. The lack of this axiom would cause the system to accept many epistemic operators in system $\mathbf{L}$ (for instance, " $x$ asserts that it asserts that $p$ " would be a different operator than " $x$ asserts that $p$ "). Axiom (L5) allows the sentences about one's own beliefs to be treated not as privileged sentences but on par with all other $L_{x} p$ type sentences. (L5) consists of two implications:
1. (L5a)
$L_{x} L_{x} p \rightarrow L_{x} p$
2. (L5b)
$L_{x} p \rightarrow L_{x} L_{x} p$.

In (L5a), it is said that if $x$ asserts that it asserts that $p$, then $x$ asserts that $p$. In other words, (L5a) expresses the theorem that a rational entity is infallible when it comes to assessing its own beliefs. In systems where the thesis of individual infallibility of an entity is assumed (the counterpart of axiom (T)), the counterpart (L5a) is a simple consequence of the thesis. In system $\mathbf{L}$, on the other hand, in the absence of a thesis of individual infallibility, one has to assume (L5a) axiomatically. This is commonly accepted in epistemic logic systems. It does not go beyond the postulates of rationality established here. However, condition (d) refers to the infallibility of the cognising entity. Of course, it is assumed that the subject has no memory disorders or difficulties in the linguistic formulation of thoughts.

The reverse implication (L5b) is more disputable - it postulates the entity's omniscience with regard to its own beliefs. According to (L5b), whenever $x$ asserts a sentence, it also asserts that it asserts that sentence. The disputability of (L5b) is further enhanced by the fact that its consequence is thesis (L12), which expresses the attribute of the entity and can be called 1negative's omniscience. According to (L12), $x$ not only knows that it asserts something but also that if $x$ does not assert sentence $p$, it asserts the sentence that $x$ does not assert sentence $p$, and so $x$ knows what it does not know. Does (L12) express the Socratic "I know that I know nothing"? With a certain understanding of the theorem, this may be so. It is easy to turn (L12) into the following form:

$$
L_{x} p \vee L_{x} \neg L_{x} p
$$


which states that this rational entity either asserts any sentence $p$ or knows (asserts) that it does not assert this sentence, i.e., $x$ has a perfect understanding of the whole range of its knowledge. This is understandable if we consider that proof (L12), besides (L5), requires (L1) as well. Due to this, the attribute of completeness is transferred to the entity's self-knowledge. In this form, the thesis about "negative" omniscience seems to enrich the capabilities of the human cognising entity. On the other hand, a weaker theorem about "positive" omniscience is open to debate. However, certain solutions about the nature of consciousness are required here. If, for instance, one accepts the theorem of consciousness as self-revealing, then (L5b) is acceptable. Given belief states are given in the intuition of experiencing (conscientia concomitans). One can also assume the entity's perfect reflexive abilities (or rather, the disposition of a perfect reflection).

The author of system $\mathbf{L}$ also allows for the possibility of extending the system to cases where only one recognising entity is given (in informal analyses of system $\mathbf{L}$ more than one member was assumed). Then, you only need to add axiom (L13) $\exists p S p$, which can be read as follows: there is sentence $p$ that is disputable. This axiom protects system $\mathbf{L}$ from the possibility of being interpreted as describing the knowledge of the Absolute. The thesis of collective infallibility (L4) would, assuming the uniqueness of the entity, be transformed into the thesis of individual infallibility and, consequently, to the thesis of omniscience. Thus, we would have a system of maximal assertion. The axiomatic acceptance (L13) excludes such a situation. There have to exist sentences that are disputable even for the sole entity. The problem is, however, how to intuitively understand this disputability as "impossible to resolve for $x$ " and "doubtful for $x$ ". Allowing an "internal" disputability should result in a contradiction of beliefs because, by definition (D1), $S p={ }_{d f} \exists x \exists y\left(L_{x} p \wedge L_{y} \neg p\right)$ disputability means that one entity asserts a sentence and the other rejects it. If the same entity asserts and rejects a sentence, it leads to a violation (L1a), unless we understand this dispute differently than the definition. 


\section{Rescher's Systems of Assertion}

Rescher ${ }^{36}$ constructed a number of systems of assertion logics, among which we can include Łośs system. The basis is the following list of axioms and rules (enriched with the modus ponens rule, substitution rule, quantifiers rule and axioms of classical logic):

(R)

$\left(\mathrm{A}_{2}\right)$

$\left(\mathrm{A}_{3}\right)$

$\left(\mathrm{A}_{4}\right)$

$\left(\mathrm{A}_{5}\right)$

$$
\begin{aligned}
& \text { If } \phi \vdash \psi \text {, then } A_{x} \phi \vdash A_{x} \psi \\
& \forall x \exists p A_{x} p \\
& A_{x} p \wedge A_{x} q \rightarrow A_{x}(p \wedge q) \\
& \neg A_{x}(p \wedge \neg p) \\
& \forall x A_{x} p \rightarrow p \\
& p \rightarrow \exists x A_{x} p \\
& A_{x} A_{x} p \equiv A_{x} p \\
& A_{x} p \vee A_{x} \neg p
\end{aligned}
$$

obligation non-emptiness conjunction non-contradiction Lincoln collective omniscience redundancy completeness

The systems are created in the following manner:

$$
\begin{aligned}
& \mathbf{A}_{1}=\{(\mathrm{A} 1),(\mathrm{A} 2),(\mathrm{A} 3),(\mathrm{R})\} \\
& \mathbf{A}_{2}=\mathbf{A}_{1} \cup\left\{\left(\mathrm{A}_{2}\right)\right\} \\
& \mathbf{A}_{3}=\mathbf{A}_{1} \cup\left\{\left(\mathrm{A}_{3}\right)\right\} \\
& \mathbf{A}_{4}=\mathbf{A}_{3} \cup\left\{\left(\mathrm{A}_{4}\right)\right\} \\
& \mathbf{A}_{5}=\mathbf{A}_{1} \cup\left\{\left(\mathrm{A}_{4}\right),\left(\mathrm{A}_{5}\right)\right\} .{ }^{37}
\end{aligned}
$$

System $\mathbf{A}_{1}$ contains a postulate of non-contradiction and a deductive closure (a rational entity is obliged to the non-contradiction of beliefs and to derive logical consequences from what one asserts), enriched with the existential postulate that every entity has at least one belief and a postulate concerning the

36 Rescher, Topics in Philosophical Logic, 250-286.

37 Instead of such formulation, it should be $\mathbf{A}_{5}=\mathbf{A}_{1} \cup \mathbf{A}_{4} \cup\left\{\left(\mathrm{A}_{5}\right)\right\}$ if the system is to be equivalent to Łośs (and Rescher argues this, although his argumentation has errors that make it less clear) (Lechniak, Przekonania i zmiana przekonań, 255). 
conjunction. ${ }^{38} \mathbf{A}_{2}$, on the other hand, adds to $\mathbf{A}_{1}$ Lincoln's thesis of collective infallibility (axiom (L4) in Łośs system) and to $\mathbf{A}_{3}$ collective omniscience - if there is no $x$ that asserts $p$, then $p$ is false. It is easy to prove that when having $\left(A_{3}\right)$, one can prove $\left(A_{2}\right)$ within system $\mathbf{A}_{1}$, i.e., system $\mathbf{A}_{3}$ contains system $\mathbf{A}_{2}$. System $\mathbf{A}_{4}$, on the other hand, complements axiom $\mathbf{A}_{3}$ system with a reduction thesis $\left(\mathrm{A}_{4}\right)$ that states omniscience and infallibility for introspection (it allows the reduction of all epistemic operators multiplied to individual) while $\left(\mathrm{A}_{5}\right)$ adds completeness to the properties of beliefs (knowledge): "The assertor is complete when it takes a specific position towards each sentence, i.e., if for every $p$ it either states $p$ or, if it does not state $p$, it states $\neg p "{ }^{39}$ System $\mathbf{A}_{5}$ is equivalent to the system set out by the following set of axioms:

$$
\begin{aligned}
& A_{x} \neg p \equiv \neg A_{x} p \\
& A_{x}(p \wedge q) \equiv\left(A_{x} p \wedge A_{x} q\right) \\
& A_{x} A_{x} p \equiv A_{x} p
\end{aligned}
$$

The following rule also applies:

$$
\text { If } \vdash \phi \text {, then } \vdash A_{x} \phi^{40} \text {. }
$$

38 The theses $\mathbf{A}_{1}$ are as follows:

$$
\begin{aligned}
& A_{x} p \wedge A_{x} q \equiv A_{x}(p \wedge q) ; \\
& A_{x} p \rightarrow \neg A_{x} \neg p ; \\
& A_{x}(p \rightarrow q) \rightarrow\left(A_{x} \rightarrow A_{x} q\right) .
\end{aligned}
$$

The rule that corresponds to Godel's rule could also be proved:
$\left(\mathrm{R}^{*}\right)$
If $\vdash \phi$, then $\vdash A_{x} \phi$.

Rescher indicates that instead of axioms (A1-A3) and rule (R), one may assume $\left(\mathrm{R}^{*}\right)$ and (2) and (3). It is easy to notice that we would then obtain a subsystem of Łośs system, a weakened implication (L1) and (L2.1) to (L2.3) and (L3) (that is system KD).

39 (Rescher, Topics in Philosophical Logic, 259) In system $\mathbf{A}_{5}$ the theses are $\left(\mathrm{A}_{5}: 1\right)$ $A_{x} \neg p \equiv \neg A_{x} p \quad$ and $\left(\mathrm{A}_{5}: 2\right) A_{x}(p \vee q) \equiv\left(A_{x} p \vee A_{x} q\right)$. Rescher stresses that there is a characteristic property in this system where for any truth-functional operator we have $F\left(A_{x} p, A_{x} q, \ldots, A_{x} r\right) \equiv A_{x}(F(p, q, \ldots, r))$.

${ }_{40}$ System $\mathbf{A}_{5}$ thus characterised cannot be placed within the system order suggested by Rescher (as a consequence of an error I wrote about earlier); there is no way to prove either $\left(A_{3}\right)$ or $\left(A_{2}\right)$ in it, i.e., this system does not allow a transfer from the sentences preceded by operator $A$ to sentences without this operator. 
Rescher also proposed a way to shift from assertion systems to standard modal logics. ${ }^{41}$ The basis of this proposal is the acceptance of necessity, which is understood collectively as recognition (assertion) by the whole population. The following definitions should be adopted $\left(A_{x}^{*} p\right.$ is an assertion in the weak sense, i.e., " $x$ does not assert contradiction $p$ ", the "asterisked" functions are weak functions):

$$
\begin{aligned}
& A_{x}^{*} p={ }_{d f} \neg A_{x} \neg p \\
& \square p={ }_{d f} \forall x A_{x} p \\
& \diamond p={ }_{d f} \exists x A_{x} p \text { (assuming that } \diamond p=_{d f} \neg \square \neg p \text { ) } \\
& \square^{*} p={ }_{d f} \forall x A_{x}^{*} p \\
& \diamond^{*} p={ }_{d f} \exists x A_{x}^{*} p^{42}
\end{aligned}
$$

As you can see, according to the above definition, sentence $p$ is necessary when it is stated by all entities and possible when there is an entity that asserts it. For weak operators, $p$ is necessary in a weak sense when all entities assert it in a weak sense. ${ }^{43}$ For the modalities that refer to a strong assertion, we have, according to Rescher, the following relationships:

- System $\mathbf{A}_{1}$ is equivalent to system $\mathbf{K D}^{44}$;

- In order to obtain system $\mathbf{K T}$, one has to strengthen $\mathbf{A}_{1}$ with axiom $\left(A_{2}\right)$ (Lincoln's thesis that guarantees the truth of the sentences stated by everyone);

- System KT4 is obtained by adding to $\mathbf{A}_{1}$ the following formula:

$$
\forall x A_{x} p \rightarrow \forall y A_{y} \forall x A_{x} p
$$

${ }^{41}$ Rescher, Topics in Philosophical Logic, 268-272.

42 There appear to be errors in the relevant definitions in Rescher, Topics in Philosophical Logic, 283).

${ }^{43}$ This quantifier interpretation of modality was proposed in the 1950s by Ludwik Borkowski (“O terminach modalnych" ("On modal terms"), Studia Logica 7 (1957)) with the difference that the quantification referred not to entities but sentence indicators.

44 Since the languages of the compared systems are different, by equivalence of systems we mean the equivalence with some translation (i.e., system at least as strong as...). 
- System KT45 is obtained by adding to $\mathbf{A}_{1}$ the formula:

$\exists y A_{y} \forall x A_{x} p \rightarrow \forall x A_{x} p$

This way of understanding necessity may seem quite controversial. Axiom (4) takes on the form "if everyone in the population asserts $p$, then every entity asserts that every entity asserts $p$ ". The logic of assertion is transformed into a system of common knowledge. ${ }^{45}$

\section{Marciszewski’s Logic of Cartesian Assertion}

Marciszewski ${ }^{46}$ presented the system Cart based on a technique similar to that employed by Łoś called the Cartesian assertion system. ${ }^{47}$ The language of this system includes individual variables (going through a set of "intelligent beings") and sentence variables "representing syntactic creations, which in grammar are called dependent clauses (oratio obliqua); in Polish they include all the clauses following $\dot{z} e$ (that). [...] Here it is enough to make a syntactic statement that expressions with sentence structure can be substituted for the discussed variables" ${ }^{48}$ The language also includes the propositional calculus conjunctions that link dependent and independent clauses, quantifiers that bind both sentence and name variables and $K$ operator read as "asserts" (or by equivalence: "believes that", "is convinced that").

System Cart is characterised by the following list of axioms (enriched with substitution, detachment and replacement rules and rules for quantifiers):

45 "Everyone knows that $p$ " (operator $E$ ): $E_{B} p \equiv(\forall x \in B) K_{x} p$.

46 Witold Marciszewski, Podstawy logicznej teorii przekonań (Warszawa: PWN, 1972), $75-88$.

${ }^{47}$ Marciszewski calls his system $\mathbf{K}$; here, to distinguish it from the standard modal logic $\mathbf{K}$, we introduce the designation Cart.

48 Marciszewski, Podstawy logicznej teorii przekonań, 75. It is necessary to correct this remark by Marciszewski: in the Cart system sentence variables represent not only dependent but also independent clauses (oratio recta) - it is enough to look at the axioms of the system. 


$$
\begin{aligned}
& \forall p\left(K_{x} p \rightarrow p\right) \\
& \neg(\forall p)\left(\neg K_{x} p \rightarrow K_{x}(\neg p)\right) \\
& K_{x}(p \rightarrow q) \rightarrow\left(K_{x} p \rightarrow K_{x} q\right) \\
& K_{x} t, \text { where } t \text { is any tautology of classical logic }
\end{aligned}
$$

The system contains a very cautious description of the entity's cognitive capabilities. (K1) states the truth of beliefs (judgements) and (K4) asserts every logical tautology. Axiom (K3), in turn, represents a principle of distribution that, together with (K4), can be reduced to the theorem of logical omniscience. Thus, we have at least system KT, enriched with a purely "prohibitive" system, that restricts the set of asserted sentences (the assertion relationship is not coherent and the set of asserted sentences is not complete) axiom (K2). The role of this axiom is limited: out of the 11 theses quoted explicite by Marciszewski, this axiom is used in the evidence of only two negative theses, namely, the theses concerning the distribution of operator $K$ into the members of the alternative (K11) stating the lack of omniscience (K14). The use of quantifier-binding sentence variables is also conditioned only by axiom (K2). Here is a list of some of the theses of system Cart:

(K5) $\quad K_{x} \neg p \rightarrow \neg K_{x} p$ (a simple consequence (K1) and (K4) and the counterpart of modal axiom (D)

(K6) $\neg\left(K_{x} p \wedge K_{x} \neg p\right)$ (the principle of non-contradiction "psychological")

(K9) $K_{x}(p \wedge q) \equiv\left(K_{x} p \wedge K_{x} q\right)$

$(\mathrm{K} 10)\left(K_{x} p \vee K_{x} q\right) \rightarrow K_{x}(p \vee q)$

(K11) $\neg \forall p \forall q\left(K_{x}(p \vee q) \rightarrow\left(K_{x} p \vee K_{x} q\right)\right)$ (the negative theorem mentioned above)

(K13) $K_{x} K_{x} p \rightarrow K_{x} p$ (a simple consequence (K1))

(K14) $\neg \forall p\left(p \rightarrow K_{x} p\right)$ (a thesis on the lack of omniscience)

(K15) $\neg \exists x \exists y\left(K_{x} p \wedge K_{y} \neg p\right)$. 
Operator $K$ may have different interpretations (such as a modal interpretation), i.e., it may be interpreted as a necessity (as is practically always the case with the knowledge or belief operator). Axiom (K2) is read by Marciszewski as follows: "Not always: if it is not necessary that $p$, then it is necessary that $\neg p$ ". The author points out that with the epistemic interpretation of this operator of necessity, one can find a justification for its theses in the theorems of Cartesian philosophy; ${ }^{49}(\mathrm{~K} 1)$ is expressed in the formulation by Descartes: "Everything that we get to know is true", from which the theorem on the undisputability of knowledge (K15), emerges; (K3) is a simplified formulation of the Cartesian principle of deduction; (K4) indicates that assertion is discretionary nature: "If a person is faced with the question of whether he or she asserts a given tautology and whether he or she has enough time to find an answer", then they can decide about each sentence whether or not it is a tautology (of course, the assumption of potential logical omniscience has to be limited to decidable calculi).

In light of the above remarks, we can see that the system of assertion logic built by Łoś (although its author went beyond the purely formal reasons in its construction) presents a specific vision of the cognising entity, which is included in the aspect of assertion. However, the non-formal implications of some of the system's theses are too strong for it to accurately describe the beliefs (even) of the idealised human cognising entity. The non-formal implications of other theses, on the other hand, seem to coincide with the relevant postulates of the theory of rational behaviour, which has been adopted here as a model to assess the degree of adequacy of system $\mathbf{L}$ theses. The system of epistemic logic expresses certain idealisations, and, therefore, its theses have been juxtaposed with those of idealistic theory, or the theory of rational behaviour. However, it cannot be said that the theses of system $\mathbf{L}$ accurately describe the states of belief of every real person.

Summarising the above remarks, one can say that the system of epistemic logic should not be treated as a general description included in every aspect

49 Marciszewski, Podstawy logicznej teorii przekonań, 43-46. 
of the human cognising entity. However, it must be imperative that its peculiar axioms are true in the model of the human cognising entity, which is determined by the accepted theory of rational behaviour. The peculiar operator of epistemic logic should become a technical term that can serve to express thoughts on certain topics with greater precision than is done by the relevant epistemic colloquial phrases.

It appears that the system by Łoś can accurately describe the beliefs of the human rational entity if axiom (L1) is weakened. The system (both by Łoś and the modifications introduced by Rescher and Marciszewski) uses quantifiers that bind sentence variables. However, the above analyses prove that these quantifiers do not perform any important functions in Łošs or Marciszewski's systems. Instead, they serve as instruments to weaken the systems, blocking the deductive possibilities of the entity. Łoś's system, for one entity in one epistemic state, appears as a very strong system that formalises the concept of knowledge, while Marciszewski's Cart logic is at least as strong as the modal system $\mathbf{K T} .^{50}$

It is worth stressing here that Łośs system is the world's first system of epistemic logic (Łoś is also the forerunner of temporal logics). ${ }^{51}$ What is par-

${ }^{50}$ It is interesting that Marciszewski treats system $\mathbf{L}$ as the logic of ordinary assertion ("it will be a type of assertion which is not characterised by conditions so strong that their fulfilment requires finding either specific types of beliefs or adopting some controversial philosophical assumptions" (Podstawy logicznej teorii przekonań, 89)) and the Cart system as the logic of knowledge. Even if one did not treat Lincoln's axiom as referring to the infallibility of an individual, Łośs logic would be a system at least as strong as KD45 while system KT seems, of course, too weak to reflect the intuition connected with the notion of knowledge. In both systems, logical omniscience and inconsistency are both accepted without reservations (similar to the Rescher's family of systems).

${ }^{51}$ It must, therefore, be surprising that under the entry "epistemic logic" in the Stanford Encyclopedia of Philosophy there is no mention of Łoś, although Łoś himself is mentioned (probably indirectly): "Modern treatments of the logic of knowledge and belief grow out of the work of a number of philosophers and logicians writing from 1948 through the 1950s. Rudolf Carnap, Jerzy Łoś, Arthur Prior, Nicholas Rescher, G.H. Von Wright and others asserted that our discourse concerning knowledge and belief exhibits systematic features that admit of an axiomatic-deductive treatment. Among the many important papers that appeared in the 1950s, Von Wright's seminal work (An Essay in Modal Logic) is widely asserted as having initiated the formal study of epistemic logic as we know it today. Von Wright's insights were extended by Jaakko Hintikka in his book Knowledge and Belief: An Introduction to the Logic of the Two Notions (1962)". 
ticularly noteworthy is the description of the epistemic operator developed by Łoś - a sentence-forming operator from one name argument and one sentence argument, which later became a standard in epistemic logic. Such operators are called realisation operators or Łośs operators and are characterised by positional logic. Realisation operator $R$ is "a kind of modal operator, simple in its basic interpretation, but at the same time allowing to interpret more complex modalities. Operator $R$ states modus, i.e., the way a given sentence, which is within the range of the operator, occurs (it is true, it occurs at a given time, it is implemented, it is an object of knowledge, etc., depending on philosophical-technical motivations which accompany the construction and application of positional logic)" ${ }^{52}$

\section{References}

Borkowski Ludwik. 1958. "O terminach modalnych" (“On modal terms”). Studia Logica 7: 7-41.

Byrd Michael. 1973. "Knowledge and True Belief in Hintikka’s Epistemic Logic". Journal of Philosophical Logic 2: 181-192.

Cherniak Christopher. 1986. "Minimal Rationality”. Mind 90 (1981): 161-180.

Chisholm Roderick M. 1963. "The Logic of Knowing". Journal of Philosophy 60: 773-775.

Fagin Ronald, Halpern Joseph, Moses Yoram, Vardi Moshe. 1995. Reasoning about Knowledge. Cambridge, MA: The MIT Press

Giedymin Jerzy. 1964. Problemy, założenia, rozstrzygnięcia (Problems, assumptions, solutions). Poznań.

Gödel Kurt. 1933. "Eine Interpretation des intuitionistischen Aussagen-kalküls". Ergebnisse eines mathematisches Kolloquiums 4: 34-40.

Haack Susan. 1978. Philosophy of Logics. Cambridge: Cambridge University Press.

Hiż Henryk. 1951. "Review: J. Łoś, Foundations of the methodological analysis of Mill's canons". Journal of Symbolic Logic 16: 58-59.

Hooker C. E. 1994. "Idealisation, Naturalism, and Rationality: Some Lessons from Minimal Rationality”. Synthese 99: 181-131.

${ }^{52}$ Jarmużek, Tkaczyk, Normalne logiki pozycyjne, 29-30. 
Jarmużek Tomasz. 2007. "Minimal Logical Systems with R-operator: Their Metalogical Properties and Ways of Extensions". In: Perspectives on Universal Logic, eds. J. Bezieau, A. Costa-Leite, 319-333. Italy: Polimetrica Publisher.

Jarmużek Tomasz. 2018. On the Sea Battle Tomorrow That May Not Happen. A Logical and Philosophical Analysis of the Master Argument. Berlin: Peter Lang.

Jarmużek Tomasz, Aleksander Parol. 2020. "On Some Language Extension of Logic MR: A Semantic and Tableau Approach”. Roczniki Filozoficzne 68, 4: 345-366.

Jarmużek Tomasz, Andrzej Pietruszczak. 2004. "Completeness of Minimal Positional Calculus". Logic and Logical Philosophy 13, 147-162.

Jarmużek Tomasz, Marcin Tkaczyk. 2015. Normalne logiki pozycyjne (Normal positional logics). Lublin: Wydawnictwo KUL.

Jarmużek Tomasz, Marcin Tkaczyk. 2019. "Expressive Power of the Positional Operator R: A Case Study in Modal Logic and Modal Philosophy". Ruch Filozoficzny LXXV, 2: 93-107.

Karczewska Anna. 2018. "Maximality of the Minimal R-logic". Logic and Logical Philosophy 27: 193-203.

Klonowski Mateusz, Krzysztof Krawczyk. 2019. "Problem wszechwiedzy logicznej. Krytyka nienormalnych światów i propozycja nowego rozwiązania" "The problem of logical omniscience. The critique of non-normal worlds and the proposition of new solution"). Filozofia Nauki 27, 1:27-48.

Kmita Jerzy, Nowak Leszek. 1968. Studia nad teoretycznymi podstawami humanistyki (Studies on theoretical foundations of science). Poznan.

Lechniak Marek. 1988. "Logika epistemiczna Jerzego Łosia a teoria racjonalnego zachowania" ("Epistemic logic of Jerzy Łoś and rational choice theory"). Roczniki Filozoficzne 36, 1: 77-89.

Lechniak Marek. 2011. Przekonania i zmiana przekonań (Beliefs and belif change theory). Lublin: Wydawnictwo KUL.

Lemmon Edward John. 1957. "New Foundations for Lewis Modal Systems". Journal of Formal Logic 22, 2: 176-186.

Lewis Clarence Irving. 1918. A Survey of Symbolic Logic. Berkeley, CA: University of California Press.

Łoś Jerzy. 1948. "Logiki wielowartościowe a formalizacja funkcji intensjonalnych". Kwartalnik Filozoficzny 17, 1-2: 59-78.

Łoś Jerzy. 1949. "Podstawy analizy metodologicznej kanonów Milla". Annales Universitas Mariae Curie-Sklodowska, sectio F, vol. II, 5, s. 269-301.

Łoś Jerzy. 1949. O matrycach logicznych. Prace Wrocławskiego Towarzystwa Naukowego. Seria B, No. 19.

Łukasiewicz Jan. 1957. Aristotle's Syllogistic from the Standpoint of Modern Formal Logic. Oxford: Clarendon Press. 
Malinowski Jacek, Krzysztof Pietrowicz, and Joanna Szalacha-Jarmużek. 2020. "Logic of social ontology and Łošs operator". Logic and Logical Philosophy 29: 239-258. Marciszewski Witold. 1972. Podstawy logicznej teorii przekonań. Warszawa: PWN. Nowak Leszek. 1974. Zasady marksistowskiej filozofii nauki. Warszawa.

Patryas Wojciech. 1979. Idealizacyjny charakter interpretacji humanistycznej. Poznań. Patryas Wojciech. 1987. Uznawanie zdań. Warszawa: PWN.

Poczobut Robert. 2000. Spór o zasadę niesprzeczności. Lublin.

Rescher Nicholas. 1968. Topics in Philosophical Logic. Reidel Publ. Dordrecht.

Suszko Roman. 1949. "Review: Jerzy Łoś, Many-valued logic and formalization of intensional functions". Journal of Symbolic Logic 14: 64-65.

Tkaczyk Marcin. 2009. Logika czasu empirycznego. Lublin: Wydawnictwo KUL.

Tkaczyk Marcin. 2013. "Negation in weak positional calculi". Logic and Logical Philosophy 22: 3-19.

Tkaczyk Marcin, Tomasz Jarmużek. 2018. “Jerzy Łoś Positional Calculus and the Origin of Temporal Logic". Logic and Logical Philosophy.

Von Wright Georg Henrik. 1951. An Essay in Modal Logic. Amsterdam.

Abstract: The paper presents Jerzy Łośs system of epistemic logic, which is the world's first system of epistemic logic. We characterise this system and give an analysis of its theses in the light of the theory of rational behaviour. We notice that some theses are adequate to the characterization of the rational belief, but some of them are too much idealization of rational behaviour. Next, we check Nicolaus Rescher's systems of assertion and relation between them and Łośs system. We also analyse so-called Carthesian system constructed by Witold Marciszewski, which is intended as improvement of Łošs system.

Keywords: epistemic logic, positional logic, Jerzy Łoś, beliefs, rational behaviour theory 